\title{
Comparative Analysis of Materials of Su-style Furniture Woodcarving in Ming and Qing Dynasty
}

\author{
Weixia Gao \\ School of Art and Textile and Clothing Engineering, Changshu Institute of Technology,Changshu, \\ Jiangsu, 215500, China \\ 1046978972@qq.com
}

Keywords: Comparative analysis, Su-style furniture, Woodcarving materials.

\begin{abstract}
Su-style furniture woodcarving skills gradually matured and perfected in different stages of Ming and Qing dynasties, and have been passed down to this day through the dynamic way of physical production. Firstly, this paper compares the woodcarving materials used by Su-style with different carving styles in Ming and Qing Dynasties, and then analyses the reasons for the change of woodcarving decoration materials used.
\end{abstract}

\section{Introduction}

From the Ming and Qing Dynasties to the present, it is not difficult to see that there are obvious differences between Su-style and other regional furniture woodcarving. These differences are mainly due to the unique carving skills of Suzhou craftsmen, which are different from those of other regional craftsmen. When craftsmen in Suzhou make furniture, they emphasize "beauty and skill" and stress the natural beauty of expressing materials. Su-style furniture retains the traditional Chinese idea of creation, and takes high-quality hardwood as the main material whose quality choice is very fastidious.

According to the archaeological period and the recognized furniture period of Ming and Qing dynasties, the Su-style furniture of Ming and Qing dynasties can be divided into two stages. The division of Ming-style and Qing-style is based on decoration style and roughly takes the mid-Qing Dynasty as the demarcation line. Due to the stability of social environment, prosperous economic development, changes in living customs and artistic interests, the technique and component decoration of furniture carving are increasing day by day, which is quite different from Ming-style decorative style. The Qing Su-style furniture woodcarving came into being. Although the decorative themes and expressive methods of furniture woodcarving by Su-style in Ming and Qing dynasties may be repeated, the focus of these two stages is quite different. Therefore, this paper is aimed at the main decorative language of furniture woodcarving by Su-style in different periods of Ming and Qing dynasties, through the works. The comparative analysis of the main decorative materials of furniture woodcarving explores the evolution law of the integrity and stages of furniture woodcarving decoration by Su-style in Ming and Qing Dynasties.

\section{The main material of Ming style}

The woodcarving materials of Su-style in Ming and Qing Dynasties mainly come from nonlocal wood, imported wood and local wood. Through the induction and arrangement of the woodcarving species of Su-style in Ming and Qing Dynasties and the consultation of Su-style furniture research experts, it is found that the main woodcarving materials of Su-style in different stages of Ming and Qing Dynasties are different from the times. Beech and rosewood are the first choice. Old mahogan, beech and phoebe nees are often used after the middle of Qing Dynasty. In addition, there were also a lot of wood species such as red sandalwood, ginkgo wood, oak hazel and so on used in the Ming and Qing Dynasties. 


\subsection{Beech}

Although at the latest Tang Dynasty there are historical records of hardwood furniture, such as red sandalwood and rosewood. In the use of furniture in the Ming Dynasty, beech wood should be earlier than hardwood such as rosewood and there is also a saying in the south of the Yangtze River that "no beech cannot be made without beech". Ancient transportation costs were high, furniture production was generally obtained raw material locally, local beech wood is the first choice for Su-style furniture woodcarving materials. Ming and Qing Su-style furniture woodcarving main materials only beech has been throughout the Ming and Qing centuries.

Beech is also known as Chinese fir. There is a record in Fan Lian's Yunjian Yimu Banknote of Ming Dynasty that "Although the slave's house of fast armor has used fine utensils, luxurious and extravagant, it is not expensive with Chinese fir since Longwan reign". Though beech has been produced in the south of the Yangtze River, Japan, Korea and other places in China, the yield of beech is the highest in the south of the Yangtze River with Suzhou as the center. According to Chinese Tree Taxonomy, "Beech is a tree from Jiangsu and Zhejiang provinces. Its nickname is"beech elm"or"big leaf elm". The wood is firm and the color is beautiful whose use is very wide and quite valuable. It is ageing wood with red color, especially known as "blood beech". Because of the preciousness and beauty of wood, the woodcarvings of Su Ming-style mostly used blood beech as the main material, and relatively less used yellow beech. Beech with natural hills overlapping, has a beautiful parabolic texture commonly known as pagoda pattern by Suzhou craftsmen, as shown in Figure 1 (a).

\subsection{Rosewood}

Rosewood is one of the representative woodcarvings of Su Ming-style furniture seen in Fig. 1 (b). It was called "Flower Palm" or "Flower Velvet" in ancient times. The collection of herbal remnants of Tang Dynasty's Chen Cangqi includes: "Rosewood comes out of Annan and Hainan, and is used as beds. It looks like red sandalwood and has a strong character." In the early Ming Dynasty, Wang You revised Gegu Yao Lun, saying "Rosewood goes out to Guangdong in the south, purple red, similar to dalbergia odorifera, but also fragrant. Its texture is ghosts, and grains are thick and light. The Qing Dynasty edition of Chieqiongzhou prefectural records also has the description of "Rosewood, purple red, similar to dalbergia odorifera, producing Li Shanzhong with a slight fragrance" ${ }^{[2]}$.

In the Republic of China, in order to distinguish between old and new rosewood, Liang Sicheng, a famous scholar, crowned the old rosewood with yellow characters. Now it has become the special title of the old rosewood in Ming and Qing Dynasties. After the liberation of biologists, the old rosewood family is called "Hainan sandalwood". Beech and Huanghua pear are both models and representatives of Su Ming-style furniture woodcarving. Huali wood is bright in color, clear in texture and beautiful in appearance. Beech color is similar to Old Huali, and their production technology also very similar ${ }^{[3]}$.

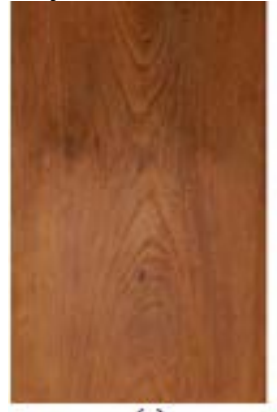

(a)

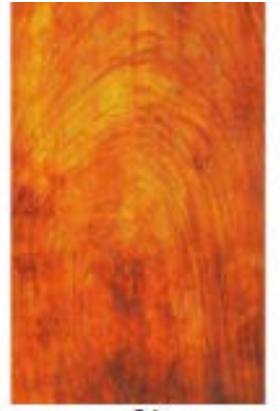

(b)

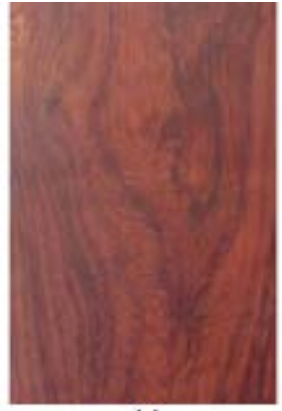

(c)

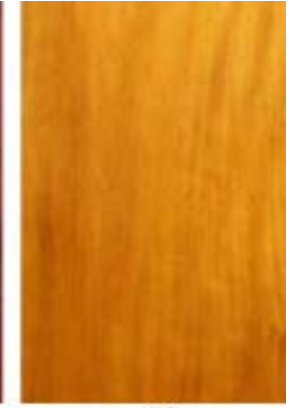

(d)

Fig.1 The main timber of Su style woodcarving in Ming and Qing Dynasties 


\section{The main material of Qing style}

\subsection{Old mahogan}

Old mahogany, also known as "purple elm", is the main wood used for furniture carving by Su-style after the early Qing Dynasty. Its wood grain is often dark brown or black stripes in deep red such as seen in Figure 1 (c). After wood sampling and slicing, the old mahogany used in Su-style furniture belongs to the genus Dalbergia, and its scientific name is "Dalbergia cochinchinensis Pierre". The application of old mahogany in furniture woodcarving of Su-style furniture is an era of prosperity and development of Qing-style furniture. Grand tutor chair and its matching tea table, round table, half table, piano case and other popular old mahogany furniture of Su-style furniture in the middle and late Qing Dynasty often carry out exquisite and gorgeous woodcarving decoration. In other words, the woodcarving of the old mahogany Su-style furniture actually reflects the artistic characteristics of the woodcarving of the Qing-style.

\subsection{Beech}

Beech wood is well-proportioned in quality, smooth in texture, and has large timber. Therefore, it is common to use Su-style soleboard furniture, which has the saying of "southern beech and northern elm" as regional furniture material characteristics. The number of Ming-style sculpture styles is more than that of Qing-style, which is related to the popular use of old mahogany after the mid-Qing Dynasty.

\subsection{Phoebe Nees}

Phoebe Nees is brown and yellow in color, fine in texture, not easy to deform and crack, fragrant, elegant and quiet in texture as seen in Fig. 1 (d). It is a fine woodcarving material for Su-styele furniture in Ming and Qing Dynasties. Among them, Phoebe zhennan S. Lee with golden silk and similar silk and satin luster is the most precious. The Qing-style phoebe nees furniture in Jiji Hall of Wufeng Immortal Hall in Liu Garden Of Suzhou is particularly suitable for Phoebe Nees Hall. These phoebe nees furniture, including taishi chairs, armchairs, square tables, tables, natural tables and so on are decorated with exquisite woodcarvings. Among them, six sets of taishi chairs in phoebe nees and six Phoebe Nees taishi chairs in Xiaotaowu in northern Liu Garden all belong to a single Ganoderma pattern. However, the back plate decoration is different, the former relief broken branches vase flower belongs to bogu pattern, while the latter carves the characters riding on the auspicious beast in the Investiture of the Gods, with mountains, rivers, trees and stones, which belongs to the theme of opera. From the existing phoebe nees furniture in the Liu Garden, we can get a glimpse of the features of Su-stye furniture in the late Qing Dynasty.

\section{Other common timber}

In addition to the above-mentioned beech, rosewood, old mahogan, phoebe nees, which are the mainstream woodcarving materials for Ming and Qing Su-style furniture, Red sandalwood, wenge, poplar, ginkgo, tussah hazelnut and cypress are also common woodcarving materials. Relatively speaking, the frequency of use is low. In this field investigation, the author only collected two pieces of woodcarving furniture made of red sandalwood from Ming and Qing dynasties. One of them was the early Qing Dynasty rosewood-legged teeth-throwing table, decorated with Ming-style scroll cloud pattern, and The other is the Qing-style red sandalwood thousand-piece desk in Suzhou gardens, but now the furniture is incomplete and the sculpture components are scattered, as shown in Fig. 2. 


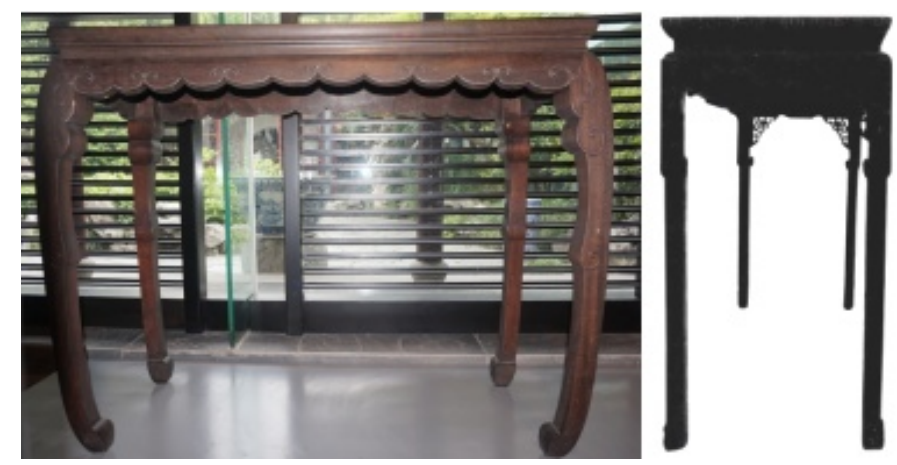

Fig.2 The Ming and Qing style Pterocarpus indicus Will furniture woodcarving

The common woodcarving species mentioned above (seen in Fig.3) can also be found in the documents of Ming and Qing Dynasties. As a book describing the prosperity of handicraft industry, commerce and urban life in the south of the Yangtze River in Wujun County of Suzhou in the Ming Dynasty, Yunjian Yimu Banknote has a detailed record of the fashion of high-quality timber such as yellow pear, wenge and boxwood popular in Suzhou at that time. The texture of wenge wood is beautiful. The woodcarving of Su-made wood furniture in the early period is simpler, while the carving work in the late Qing Dynasty is tedious. After boarding, the boxwood is light yellow, with tough texture, delicate texture and moderate hardness. Because of its slow growth, there are very few materials, which are mainly used for matching other Su-style furniture. They are generally used as independent carvings or engraving patterns embedded in furniture panels. The Su-style furniture made of common boxwood is very rare ${ }^{[4]}$.

Although the texture of Ginkgo biloba wood is not colourful, it is delicate and tough, easy to process, and does not warp. It has luster, special medicinal fragrance, and strong resistance to borers. It is generally used as sculpture materials for Su-style cabinets, desks, long tables, shelf beds and other furniture varieties.

The quality of tussah hazelnut wood produced in the alluvial plain of the Yangtze River is excellent in traditional culture. Nowadays, besides Suzhou, there are also relics of tussah hazelnut furniture in Yangzhou, Nantong and Eastern Zhejiang. The shape and decorative style of the furniture are similar, which may be influenced by the regional cultural transmission and exchange at that time. The oak grain is similar to the wenge wood, its texture is hard, and its long surface is bright and red sandalwood ${ }^{[5]}$.

The cypress is warm in color and fine in texture. The cypress used in Su-style furniture and woodcarving is a local yellow cypress. The new section is yellowish and has a mellow fragrance. Yellow tar is of great oiliness, corrosion resistance and insect resistance, and is not easily deformed. Besides being used as woodcarving materials for Su-style furniture, yellow tart is often used as large panel materials such as chairs and stools, cabinets and doors. 

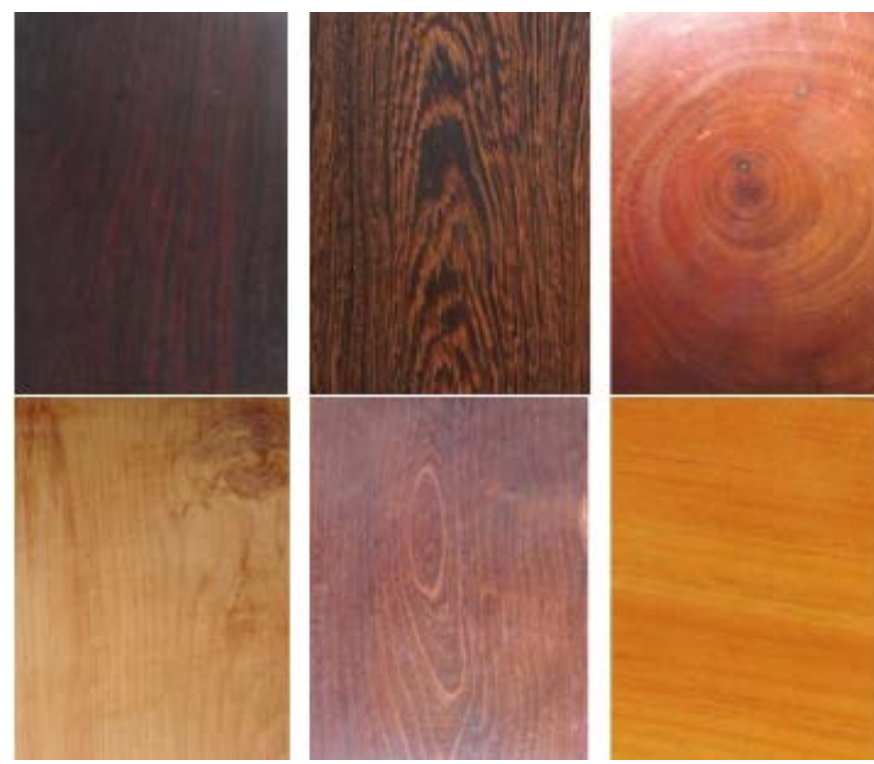

Fig.3 Ming and Qing Dynasties Su style furniture woodcarving other common timber

\section{Reasons for the age evolution of timber}

The greatest change of woodcarving materials used by Su-style furniture in Ming and Qing Dynasties was that old mahogan replaced rosewood and beech as the most important materials after the middle of Qing Dynasty. At the end of the Ming Dynasty, the precious hardwood species such as rosewood, which was purchased by the government and the folk trade in Nanyang (the name of Southeast Asia during the Ming and Qing Dynasties), were almost cut down. At the latest, the furniture of Su-style furniture also stopped abruptly in the mid-Qianlong Period. The Su-style rosewood furniture, which was produced occasionally after Jiaqing and Daoguang, was mostly original materials or materials. After the early Qing Dynasty, the old mahogany, which is rich in resources, excellent in material quality and accords with the aesthetic taste of users, has been replaced by the mainstream new material and flowed into China in large quantities.

Beech, unlike old mahogany and rosewood, has a distinct period of use in woodcarving of Su-style furniture. It runs through the whole process of development of Su-style furniture. On the one hand, because of the prosperous urban economy and courtyard construction in Suzhou during the Ming and Qing Dynasties, it is popular with the local custom of "hackberry before and after beech", which has both the symbolic implication of "moderation" and "good governance of the family". It also provides abundant and high-quality material resources for the production of woodcarving furniture. On the other hand, the distinct pagoda pattern, landscape pattern and the warm and moist wood character of beech wood always cater to the aesthetics of scholars and nobles in the Ming and Qing Dynasties, and has a broad consumer base.

\section{Acknowledgements}

This research was financially supported by Research Project of Changshu Institute of Technology (Grant NO.KYZ2017103Z), Jiangsu Provincial Philosophy and Social Science Fund (Grant NO.2018SJA1373), 2017 Major Projects of the National Social Science Fund (Grant NO.17ZDAO20),Design Morphology Study and 2018 Shanghai Design School IV Category of Top Disciplines Funded Projects: Home Fashion Products Overall Design (Grant NO.DB1R202).

\section{References}

[1] Chai Yi Jiang. Excellent ancient furniture[M].Shanghai Bookstore press, pp105-113,2003.

[2] Wu Shaohua. Furniture [M]. Shanghai: Xue Lin publishing house, pp6-8,2005. 
[3] Liu Wenzhe. Examples of ancient furniture appraisal in China [M]. Beijing: Hua Ling publishing house,pp78,2010.

[4] Wang Wenzhong.Nanmu growth characteristics and species [J]. China Timber, vol1,pp30-31,2015.

[5] Xi Hu Jian.Tien Gong charm:Ming and Qing Dynasties Su-style furniture collection collection Jane [M]. Beijing: Studio of Glorious Treasures publishing house,pp39,2007. 